Cancer Causes Control. 2020 October ; 31(10): 891-904. doi:10.1007/s10552-020-01330-z.

\title{
ADOLESCENT DAIRY PRODUCT AND CALCIUM INTAKE IN RELATION TO LATER PROSTATE CANCER RISK AND MORTALITY IN THE NIH-AARP DIET AND HEALTH STUDY
}

\author{
Tuo Lan ${ }^{1}$, Yikyung Park ${ }^{2}$, Graham A. Colditz ${ }^{2}$, Jingxia Liu², Molin Wang ${ }^{3,4,5}$, Kana Wu ${ }^{6}$, \\ Edward Giovannucci ${ }^{4,5,6}$, Siobhan Sutcliffe ${ }^{2, *}$ \\ ${ }^{1}$ Department of Occupational and Environmental Health, College of Public Health, The University \\ of lowa, lowa City, IA \\ ${ }^{2}$ Division of Public Health Sciences, Department of Surgery; and the Alvin J. Siteman Cancer \\ Center, Washington University School of Medicine, St. Louis, MO \\ ${ }^{3}$ Department of Biostatistics, Harvard T. H. Chan School of Public Health, Boston, MA \\ ${ }^{4}$ Department of Epidemiology, Harvard T. H. Chan School of Public Health, Boston, MA \\ ${ }^{5}$ Channing Division of Network Medicine, Department of Medicine, Harvard Medical School and \\ Brigham and Women's Hospital, Boston, MA \\ ${ }^{6}$ Department of Nutrition, Harvard T. H. Chan School of Public Health, Boston, MA
}

\begin{abstract}
Purpose-Although a growing body of evidence supports an early-life contribution to prostate cancer (PCa) development, few studies have investigated early-life diet, and only three have examined early-life dairy product intake, a promising candidate risk factor because of its known/ suspected influence on insulin-like growth factor levels and height.
\end{abstract}

Methods-We used recalled dietary data from 162,816 participants in the NIH-AARP Diet and Health Study to investigate associations for milk, cheese, ice cream, total dairy, and calcium intake at ages $12-13$ years with incident total $(n=17,729)$, advanced $(n=2,348)$, and fatal PCa $(n=827)$ over 14 years of follow-up. We calculated relative risks (RRs) and 95\% confidence intervals (CIs) by Cox proportional hazards regression.

Results-We observed suggestive positive trends for milk, dairy, and calcium intake with total and/or advanced $\mathrm{PCa}$ (p-trends=0.016-0.148). These trends attenuated after adjustment for additional components of adolescent diet, particularly red meat and vegetables/potatoes. In contrast, suggestive inverse trends were observed for cheese and ice cream intake with total and/or

Terms of use and reuse: academic research for non-commercial purposes, see here for full terms. https://www.springer.com/aamterms-v1

*Corresponding author Siobhan Sutcliffe: tel: 314-362-3788; sutcliffes@wustl.edu.

Publisher's Disclaimer: This Author Accepted Manuscript is a PDF file of an unedited peer-reviewed manuscript that has been accepted for publication but has not been copyedited or corrected. The official version of record that is published in the journal is kept up to date and so may therefore differ from this version. 
advanced PCa (p-trends $=0.043-0.153$ ), and for milk, dairy, and calcium intake with fatal PCa (ptrend $=0.045-0.117)$.

Conclusion-Although these findings provide some support for a role of adolescent diet in increasing PCa risk, particularly for correlates of milk intake or overall dietary patterns, our protective findings for cheese and ice cream intake with PCa risk and mortality, and for all dairy products with PCa mortality suggest alternative explanations, such as the influence of early-life socioeconomic status, and increased PCa screening, earlier detection, and better PCa care.

\section{INTRODUCTION}

An estimated 1,276,106 men were diagnosed and 358,985 died from prostate cancer (PCa) in 2018 worldwide, making it the second most common and fifth most lethal cancer globally [1]. Despite persistent efforts to elucidate the etiology of PCa, few modifiable risk factors have been identified [2]. To date, most epidemiologic studies have focused on mid- to laterlife exposures, but studying earlier-life exposures - for instance, those experienced during adolescence when the prostate grows and develops rapidly - may represent a promising new avenue of research [3]. In rodent studies, stronger associations have been observed for pubertal than adult exposures with prostate lesion development [4-6], and in humans, mathematical models suggest that the first genomic alteration in PCa development may occur as early as puberty [7]. In line with these findings, PCa precursor lesions and even small PCa foci have been observed in men as young as their twenties and thirties [8-15], and differences in the prevalence of these lesions [16], as well as in PCa incidence and mortality, have been observed by race in men as young as their thirties and forties [17].These findings suggest that exposures responsible for these differences must have occurred years to decades earlier, similar to hypothesized for other cancers, including those of the breast, colorectum, endometrium, and pancreas [18-20].

Of the many candidate risk factors studied in relation to $\mathrm{PCa}$, diet, particularly dairy product and calcium intake, is among the most promising [21]. In recent systematic reviews and meta-analyses, positive associations have been observed for adult intake of both dairy products and calcium [22-25]. These foods and nutrients may possibly increase PCa risk by several potential mechanisms, including suppression of $25(\mathrm{OH})$ vitamin D conversion to $1,25(\mathrm{OH}) 2$ vitamin $\mathrm{D}$, a molecule shown to increase cellular proliferation and reduce cellular differentiation in vitro, as well as elevation of insulin-like growth factor 1 (IGF-1) levels [26]. This latter mechanism is particularly relevant for adolescence because increased IGF-1 levels may alter the timing of onset and speed of puberty [27], as well as attained height [28], all of which are suspected or established PCa risk factors [29-33]. Consistent with this hypothesis, positive associations have been observed for early-life dairy product intake with adolescent height, height growth, and attained height in the small number of studies conducted [34-38]. Although findings from previous studies of early-life dairy product intake and PCa have been less supportive [39-41], wide differences across these studies with respect to geography (Sweden, Britain, and Iceland) and dairy product intake ( $<0.5 \mathrm{cup} /$ day up to 10 glasses/day), as well as study design characteristics, such as exposure assessment (measured household intake versus 6-7 decades-long individual recall), study

Cancer Causes Control. Author manuscript; available in PMC 2021 October 01. 
design (case-control versus cohort), and sample size ( $\mathrm{n}=41$ to $346 \mathrm{PCa}$ cases), may explain their variation in findings.

To address some of these limitations, we performed an ambidirectional analysis of adolescent dairy product (cow's milk, cheese, and ice cream) and calcium intake with PCa risk and mortality in the large National Institutes of Health - American Association of Retired Persons Diet and Health Study (AARP Study).

\section{MATERIALS AND METHODS}

\section{Study population and design}

The AARP Study is an ongoing cohort study of AARP members aged 50-71 years at enrollment in 1995-1996. Participants were recruited from six states (California, Florida, Louisiana, New Jersey, North Carolina, and Pennsylvania) and two metropolitan areas (Atlanta and Detroit). At baseline, 342,099 male participants completed a mailed, selfadministered questionnaire regarding their demographic and lifestyle characteristics, including their diet in the past year. In 1996-1997, 213,090 of these participants completed a second risk factor questionnaire (RFQ) that inquired about additional lifestyle characteristics, including their adolescent diet (ages 12-13 years). Finally, in 2004, participants completed a follow-up questionnaire to update and expand their medical and lifestyle information. All participants are followed for cancer incidence through linkage with cancer registries in the eight original recruitment areas and states where AARP members commonly relocate. Vital status is obtained from the US Social Security Administration Death Master File, National Death Index, cancer registries, questionnaire responses from next of kin, and responses to other mailings [42]. The AARP Study was approved by the Special Studies Institutional Review Board of the National Cancer Institute.

We limited the present analysis to men who responded to the RFQ $(n=213,090)$. Additional exclusions were men who: a) completed the baseline questionnaire $(n=15,760)$ or RFQ $(n=3,424)$ by proxy; $b)$ were diagnosed with cancer before completing the RFQ $(n=15,703)$; c) were missing information on $\geqslant 4$ adolescent food items $(n=4,121)$ to avoid imputing a large number of food item values; d) reported extreme adolescent energy intake ( $<500$ or $>4,500 \mathrm{kcal} / \mathrm{day}, \mathrm{n}=10,003$ [43]); or e) did not complete all adolescent dairy items $(\mathrm{n}=1,263)$, except for skim milk, which was not commonly consumed when participants were adolescents ( $92.5 \%$ of participants reported no skim milk intake). These exclusions left 162,816 participants in the analysis.

\section{Adolescent dairy and calcium intake assessment}

The RFQ included a 37-item food frequency questionnaire (FFQ) about participants' diet at ages 12-13 years (Appendix Figure 1 [44]). Food items were chosen because of their major contributions to nutrients of greatest interest for cancer at the time of FFQ development: fat, fiber, beta-carotene, and vitamin C. Nine frequency options were included for each item, ranging from never to $\geqslant 2$ times/day. Portion size was not assessed on the FFQ. We assigned missing values to the median for the study population. 
We calculated the frequency of total dairy intake as the sum of whole milk, cheese, and ice cream intake, and we modeled each of these exposures in times/week. We also performed sensitivity analyses using cut-off points from previous analyses of milk consumption $(<1$ versus $\geq 1$ time/day [39]; and $₫-4$ times/week [ $₫ 3.5$ times (or cups)/day] as the reference group [41]). Calcium intake was calculated by matching each food item to foods reported by boys aged 12-13 years on the US Department of Agriculture 1965-66 Household Food Consumption Survey, the first nationwide individual food consumption survey. These data were used to estimate: 1) portion size as the median portion size for boys aged 12-13 years; 2) calcium content; and 3) frequency for the highest category as the median age- and sexspecific intake frequency ( 2 servings/day, except for whole milk, for which 3 servings/day was assigned). Calcium intake was then estimated as the product of portion size, calcium content, and intake frequency. We divided calcium intake by total adolescent energy intake (calculated in the same manner as for calcium intake) and modeled it as quintiles.

\section{PCa assessment}

Information on $\mathrm{PCa}$, including grade (histological) and stage (SEER disease extent and summary stage), was obtained from state cancer registries and information on PCa death was obtained from the National Death Index Plus.

We defined total PCa as a first primary diagnosis of PCa (ICD-9 185 or ICD-10 C61) and advanced PCa as stages T3-T4, N1, M1, or PCa death. Additional PCa outcomes were more advanced PCa (advanced PCa excluding stage T3), fatal PCa (PCa death), and early-onset $\mathrm{PCa}$ (PCa diagnosed at age $<65$ [45], approximately the 25th percentile of age at diagnosis in the AARP Study). We examined early-onset PCa because we hypothesized that early-life exposures might lead to earlier PCa development.

\section{Statistical analysis}

We explored potential confounding by examining the distribution of covariates by frequency/quintile of total dairy and calcium intake. Age-adjusted associations were investigated by Cox proportional hazards regression. Men contributed time-at-risk from the month of return of the RFQ to the month of PCa diagnosis, loss to follow-up, death, or December 31th, 2011, whichever came first. P-trends were calculated by assigning the midpoint (or the weighted median for lower and upper categories) for each intake frequency category; and the median for each quintile.

We performed adjustment in a sequential fashion. Our first set of models included only variables that could serve as potential confounders or could address detection bias (age; adolescent energy intake; race; family history of PCa; education; marital status; smoking history; adult alcohol intake; adult body mass index [BMI]; adult waist circumference; adolescent and adult physical activity; history of prostate-specific antigen [PSA] tests, digital rectal examinations [DREs], and diabetes; and father's occupation). Our second set included additional variables that might potentially serve as either confounders or mediators (adolescent BMI and attained height). Finally, our third set included adult intake of milk, cheese, ice cream, dairy products, and calcium, as appropriate, to control for the correlation between adolescent and adult dietary exposures, and our fourth set included all other 
adolescent foods or food groups (red meat, grains, vegetables, fruits, potatoes, and sweets) to determine whether observed associations were specific to our exposures of interest or were observed because of correlations between foods. As few differences were observed between our second and third sets of models, we limited our presentation to the age-adjusted, third set, and fully-adjusted models.

To further explore the independent influence of adolescent dairy and calcium intake on PCa, we ran several stratified/restricted analyses, including analyses: 1) stratified by tertile of adult milk, cheese, ice cream, total dairy, and calcium intake; 2) stratified by father's occupation; and 3) restricted to men with at least two PSA tests and two DREs in the 3 years before the RFQ. We also performed subgroup analyses restricted to men $<55$ years of age at the time of completion of the RFQ because more accurate recalled adolescent dietary data have been observed in participants $<55$ (mean $r=0.30-0.67$ [46-48]) than $\geqslant 55$ years of age $(r=0.12-0.31[49-51])$ in previous studies.

Finally, as food availability varied greatly over the time period that participants entered adolescence (1936-1958), we performed stratified analyses to determine whether associations were modified by passing through puberty during the Great Depression and World War II (WWII) versus later. Furthermore, because puberty may last up to 19 years of age, but our dietary exposure was limited to early adolescence, we created an additional category to capture men who may have entered puberty during WWII, but completed it after the war. Thus, in total, we investigated three strata of men: those who passed through puberty before the end of WWII, those who entered puberty during WWII but completed it after WWII, and those who passed through puberty after WWII.

\section{RESULTS}

Of the 162,816 eligible participants, 17,729 were diagnosed with any PCa, 2,348 with advanced PCa, and 827 with fatal PCa. On average, men were in their early 60 s when they enrolled, and the majority were non-Hispanic White, had completed some post-secondary education, and were married. In adolescence, they tended to be normal weight (mean $\mathrm{BMI}=21.6-21.8 \mathrm{~kg} / \mathrm{m}^{2}$ ) and to engage in daily physical activity, whereas in later adulthood, they tended to be overweight (mean $\mathrm{BMI}=26.8-27.6 \mathrm{~kg} / \mathrm{m}^{2}$ ) and to engage in less physical activity (Table 1). Most of the cohort had also smoked cigarettes and been screened for PCa.

In adolescence, $41 \%$ of participants consumed dairy products $1-2$ times/day, with smaller proportions consuming $<1$ time/day ( $12 \% \leqslant 4$ times/week and $11 \% 5-6$ times/week) and $\geqslant 2$ times/day (20\% 3 times/day and $16 \% \geqslant 4$ times/day). The most common dairy product consumed was whole milk ( $76 \%$ of servings). Adolescent calcium intake ranged from $66-$ $318 \mathrm{mg} / 1000 \mathrm{kcal}$ in the lowest quintile to $627-1675 \mathrm{mg} / 1000 \mathrm{kcal}$ in the highest quintile. On average, $74 \%$ of calcium was derived from dairy sources (primarily milk). Adolescent dairy and calcium intake were only modestly correlated with adult intake (Spearman rank correlation coefficient $=0.22,0.19,0.02,0.03$, and 0.18 for whole milk, cheese, ice cream, dairy, and calcium intake, respectively).

Cancer Causes Control. Author manuscript; available in PMC 2021 October 01. 
Compared to men with low adolescent dairy and calcium intake, those with high intake were more likely to be non-Hispanic White, well-educated, and married (Table 1). They were also more likely to have had a higher social class during adolescence based on their father's occupation; have been more physically active and consumed milk with greater frequency, and vegetables and red meat with lesser frequency, during adolescence; have a lower adult BMI; consume more dairy and calcium as adults; have a family history of PCa; be a nonsmoker; and have been screened for PCa at least twice. They were also less likely to have diabetes. Focusing on adolescent dairy intake only, men with a higher intake were slightly younger; more likely to have passed through adolescence after WWII; and consumed cheese and ice cream with greater frequency, and grains with lesser frequency, during adolescence. In contrast, men with higher adolescent calcium intake were slightly older; more likely to have passed through adolescence during the Great Depression/WWII; and consumed ice cream less frequently during adolescence.

In age-adjusted analyses, greater adolescent milk intake was associated with an increased risk of total PCa (p-trend=0.004), whereas cheese and ice cream were not (Table 2). Positive trends were observed when these three dairy items were combined (p-trend $=0.006$ ) and when adolescent calcium was examined ( $\mathrm{p}$-trend $<0.001$ ). In analyses adjusted for lifestyle and medical characteristics, similar, albeit slightly attenuated, trends were observed for milk, dairy, and calcium, and a non-significant inverse trend was observed for ice cream (ptrend=0.110). Trends for milk, dairy, and calcium attenuated further and became nonsignificant after adjustment for other components of adolescent diet, particularly red meat and vegetables. In contrast, the inverse trend for ice cream strengthened and became significant after further adjustment for other adolescent food groups ( $\mathrm{p}$-trend=0.046). A similar pattern of findings was observed for early-onset PCa, although all fully-adjusted trends were weaker and non-significant (data not shown).

Similar to findings for total PCa, greater adolescent milk, dairy, and calcium intake were associated with significant or suggestive increased risks of advanced PCa in age-adjusted analyses (Table 3). Inverse trends were observed for cheese and ice cream. Trends for milk, dairy, and calcium attenuated after adjustment for adolescent and adult lifestyle and medical characteristics, and attenuated further to non-significant estimates after additional adjustment for other components of adolescent diet, particularly red meat, potatoes, and sweets. Inverse trends for cheese persisted after adjustment, whereas those for ice cream attenuated slightly, particularly after adjustment for adolescent sweets. Generally similar results were observed for early-onset advanced $\mathrm{PCa}$ (data not shown), but a slightly different pattern was observed for more advanced PCa. Null associations were observed for milk, dairy, and calcium in fully-adjusted models, whereas suggestive inverse trends were observed for cheese and ice cream (Appendix Table 1).

With respect to fatal PCa, a different pattern of findings was observed for adolescent milk, dairy, and calcium intake than with total, advanced, and more advanced PCa. No associations were observed in age-adjusted analyses, whereas suggestive inverse trends were observed in fully-adjusted models, particularly after adjustment for adolescent red meat and potatoes (Table 4). Associations of similar direction and magnitude, but minimal statistical 
significance, were observed for cheese and ice cream in age- and multivariable-adjusted models.

In stratified analyses, no clear patterns were observed: 1) across strata of adult dairy and calcium intake; 2) across strata of father's occupation; 3 ) in men who had $\geqslant 2$ PSA tests and DREs in the three years before the RFQ; 4$)$ in younger men ( $<55$ years) at the time of exposure assessment; and 5) across strata of calendar time during which participants passed through adolescence. Similar findings were also observed in sensitivity analyses using dairy and milk cut-off points from previous analyses.

\section{DISCUSSION}

In this large, ambidirectional cohort analysis, we observed several associations for adolescent dairy and calcium intake, but they varied by type of dairy product, adjustment variables, and PCa outcome. In age- and lesser-adjusted multivariable analyses, suggestive positive trends were observed for milk, dairy, and calcium intake with risks of total and advanced PCa, whereas inverse trends were observed for cheese and ice cream. Positive trends for milk, dairy, and calcium attenuated after further adjustment for additional components of adolescent diet, particularly red meat and vegetables/potatoes, suggesting that these additional components or perhaps the totality of diet (e.g., a dietary pattern) may have been responsible for the original positive trends. The opposite pattern of findings was observed for fatal PCa, with suggestive inverse trends for milk, dairy, and calcium, particularly after adjustment for adolescent red meat and potatoes. Trends for cheese and ice cream were also inverse in direction, but not statistically significant.

Our findings for adolescent dairy, milk, and calcium intake are difficult to compare to the small body of literature on this topic because of wide differences across studies, particularly with respect to dairy and milk intake. Comparing our findings to those from the study with the most similar distribution of dairy intake - the British Boyd Orr Study [41] - our findings differ from their statistically null, but suggestively inverse, associations for measured household dairy and milk intake at a mean age of 8 years and PCa risk in both minimallyadjusted analyses and those adjusted for other components of childhood diet (i.e., fruit intake; multivariable-adjusted odds ratio [OR] comparing $\geqslant 1.2$ to $<0.5$ cups of milk/ day $=0.41,95 \%$ confidence interval $[\mathrm{CI}]: 0.16-1.05$, $\mathrm{p}$-trend $=0.16$ ). These differences persisted even when we used similar intake categories as the Boyd Orr Study.

The other two previous studies were conducted in Iceland [39] and Sweden [40] where dairy and milk intake was and is still more common than in the United States. Nevertheless, our age- and lesser-adjusted findings for total and advanced PCa are in general agreement with those from the previous Icelandic study that observed positive associations between recalled adolescent milk intake and total (OR=1.26, 95\% CI: 0.90-1.75) and advanced PCa $(\mathrm{OR}=2.88,95 \% \mathrm{CI}: 1.14-7.26)$ comparing $\geqslant 1$ to $<1$ time/day in lesser-adjusted analyses. Our magnitudes of association may potentially have been weaker because of our likely lesser distribution of milk intake in the highest category. However, our fully-adjusted attenuated findings differ from their persistent fully-adjusted results (OR=1.40, 95\% CI: 0.99-1.97 for total $\mathrm{PCa}$, and $\mathrm{OR}=3.22,95 \% \mathrm{CI}: 1.25-8.28$ for advanced $\mathrm{PCa}$ ) for reasons that are unclear, 
but may possibly relate to differences in dietary correlates and patterns by geography. Finally, although our findings differ from the null association observed in the previous Swedish study (OR=0.8, 95\% CI: $0.5-1.4$ comparing 10 to 3 glasses of whole milk/day), their comparisons of adolescent milk intake were considerably higher than ours, essentially fitting within our top category and perhaps making it difficult to detect associations across these higher categories. Thus, overall, it is difficult to comment on the consistency of our findings for PCa risk with the literature. In addition, no previous studies have examined fatal PCa separately, precluding comparisons with our suggestive inverse findings.

In contrast to our findings for total dairy, milk, and calcium intake, our findings for cheese and ice cream tended to be inverse, with occasional strengthening or weakening after adjustment for other components of adolescent diet, particularly vegetable, red meat, and sweet intake. These findings differ from the null results observed for adolescent cheese intake in the previous Swedish study [40], although it is possible that their smaller sample size precluded detecting weaker associations. To our knowledge, no studies have examined adolescent ice cream intake to date.

Overall, our variable findings across dairy products, adjustment variables, and PCa outcomes may be interpreted in several ways. First, it is possible that our attenuated findings for milk, dairy, and calcium intake after adjustment for other components of adolescent diet suggest that these other components (red meat and vegetables/potatoes) are either more important than or act together with dairy products to influence PCa risk. These additional dietary components or patterns are plausible risk factors for PCa risk, as red meat intake has been found to increase exposure to mutagenic heterocyclic amines, polycyclic aromatic hydrocarbons, N-nitroso compounds, and heme iron [52, 53]; and overall dietary patterns, such as a "Western" or "meat and potatoes" pattern, have been associated with earlier puberty [54-60] and greater attained height [60] in some studies. However, why these additional dietary components or patterns would serve to raise PCa risk but lower PCa mortality is unclear.

Another possible explanation for our milk, dairy, and calcium findings could be residual detection bias by increased PCa screening and a survival advantage from earlier diagnosis and better PCa care. Although adjustment for PCa screening and restriction to men who had at least two PSA tests and DREs in the three years before analytic baseline did not appreciably alter our findings, the observed differences in PCa screening history at baseline by adolescent dairy and calcium intake may speak to additional differences after baseline that we could not control for in our analyses. Residual detection bias by greater $\mathrm{PCa}$ screening frequency and a survival advantage from earlier PCa detection and better PCa care among men with higher adolescent dairy and calcium intake and their dietary correlates could explain both the weakly positive trends with risks of total and advanced PCa (which was primarily T3 disease), and the protective trends for fatal PCa. Without this possible detection bias and survival advantage, our findings may have been more similar to the null results observed in the previous Swedish study, which was conducted before PSA screening became widespread. 
In contrast to findings for milk, dairy, and calcium intake, our generally inverse trends for cheese and ice cream intake are unlikely to be explained by increased PCa screening or a protective, nutritional component exclusive to cheese and ice cream. Instead, we believe a more plausible explanation is that greater adolescent cheese and ice cream intake, particularly in the 1930-50s, reflects other protective aspects of participants' early-life exposures, such as greater early-life socioeconomic status. We attempted to control for early-life socioeconomic status by adjusting for father's occupation, but residual confounding may still have occurred. Although the literature on early-life socioeconomic status and PCa risk is very small, some evidence exists to suggest it may be important. One study found a protective association for parental car ownership during childhood/ adolescence with non-aggressive PCa [61], but findings for father's occupation have been mixed [40, 61-63]. Alternatively, greater adolescent ice cream intake may potentially capture other factors or biologic processes (e.g., lesser stress and anxiety) [64] protective for $\mathrm{PCa}$, as ice cream intake has been found to protect against other conditions, such as diabetes, for reasons that are still unclear [65].

Despite the inconclusiveness of our findings, our study had many strengths. The ambidirectional data collected in the AARP Study allowed us to establish a temporal relation between adolescent diet and PCa onset, and to avoid concerns of differential recall bias. Our large sample size also gave us sufficient power to detect associations of smaller magnitude and the detailed data collected allowed us to control for many potential confounders. Our study also had several weaknesses. Although our study was amdirectional and we performed analyses restricted to younger men ( $<55$ years of age), adolescent diet was still assessed by recall several decades after adolescence, which may have led to non-differential exposure misclassification and an attenuation of our findings towards the null. In addition, only diet earlier in puberty was assessed, which may not have been reflective of diet throughout puberty. We attempted to address this concern by performing stratified analyses among men whose diet was unlikely to have changed during puberty (either entirely before or after WWII), with similar findings as in our main analysis. Our adolescent diet FFQ was also limited to questions on the frequency, but not portion size, of only 37 food items rather than a full FFQ that typically includes $>100$ items. However, imputation of portion size using contemporary national data should have helped to reduce the former concern and inclusion of several of the major contributors to dairy intake, especially at the time of participants' adolescence, should have helped to reduce the latter concern.

In summary, in one of the few studies to investigate early-life diet and PCa risk, we found conflicting evidence for a role of adolescent diet in PCa development. Although our attenuated, multivariable-adjusted findings for milk, dairy, and calcium intake with PCa risk provide some support for a role of dietary correlates of milk intake (red meat and potatoes/ vegetables) or overall dietary patterns in increasing PCa risk, our protective findings for cheese and ice cream with PCa risk and mortality, and for all dairy products with $\mathrm{PCa}$ mortality suggest alternative explanations. These include the possible influence of early-life correlates of adolescent cheese and ice cream intake (e.g., early-life socioeconomic status) on PCa risk and mortality, and/or the possible influence of increased PCa screening, earlier detection, and better PCa care among those with greater adolescent milk intake. Additional 
studies with further early-life exposure information and more detailed PCa screening data may help us better understand these associations.

\section{ACKNOWLEDGMENTS}

We thank Dr. Linda Liao for assistance with acquiring AARP Study data, and Dr. Stephanie Smith-Warner, Sherry Yaun, and Tao Hou for assistance defining prostate cancer outcomes. This analysis was funded by the BarnesJewish Hospital Foundation, the Alvin J. Siteman Cancer Center, and the Institute for Clinical and Translational Sciences.

\section{Appendix}

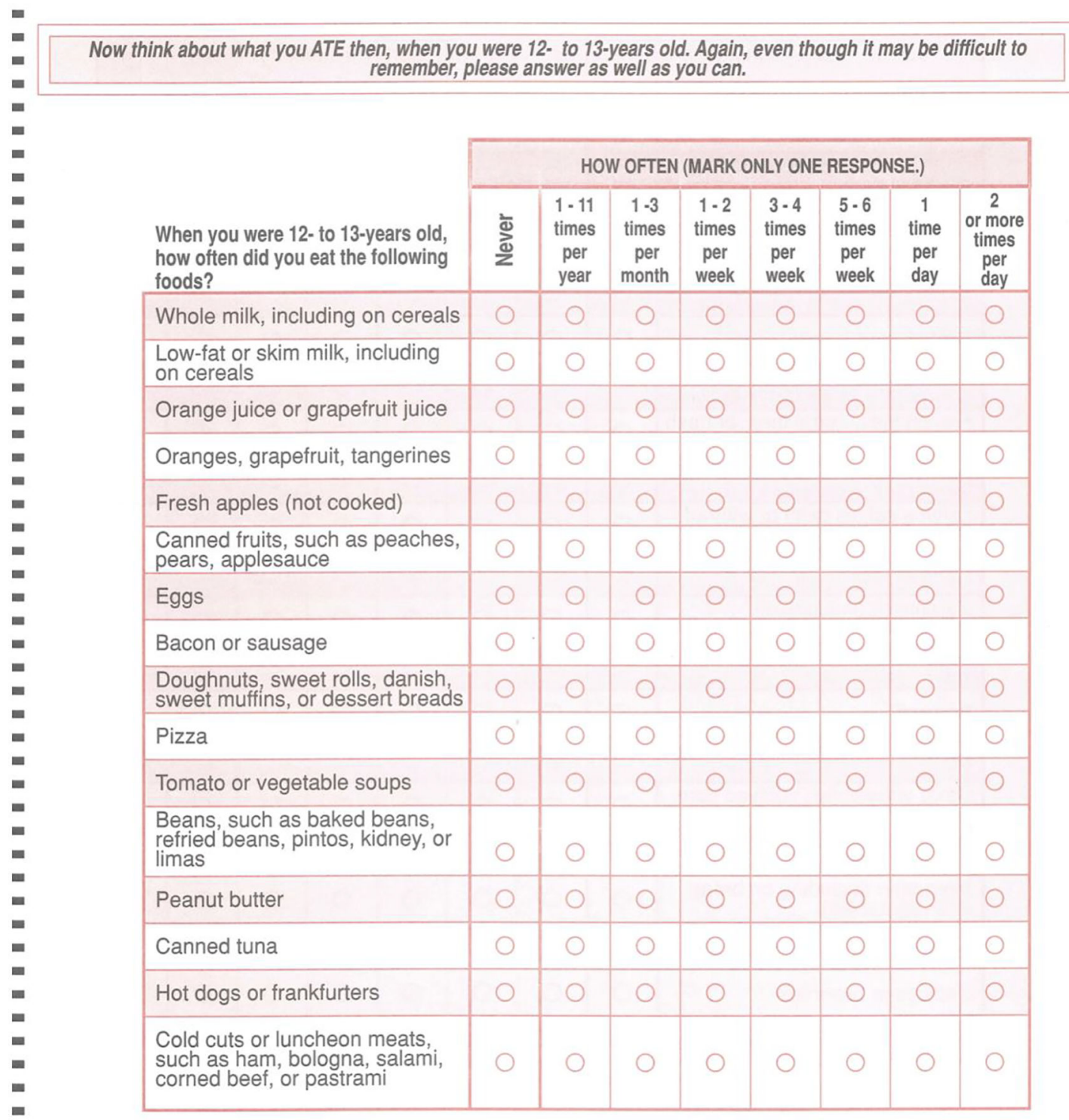

Cancer Causes Control. Author manuscript; available in PMC 2021 October 01. 


\section{9. (continued)}

When you were 12- to 13-years old, how often did you eat the following foods?

\begin{tabular}{|c|c|c|c|c|c|c|c|c|}
\hline & & & & & & & & \\
\hline Cheese or cheese spreads & 0 & 0 & 0 & 0 & 0 & 0 & 0 & 0 \\
\hline $\begin{array}{l}\text { Ground beef in hamburgers, } \\
\text { cheeseburgers, meatloaf, } \\
\text { meatballs, casseroles }\end{array}$ & 0 & 0 & O & $\bigcirc$ & 0 & 0 & 0 & O \\
\hline $\begin{array}{l}\text { Roast beef or steak (including in } \\
\text { sandwiches) }\end{array}$ & 0 & 0 & 0 & O & O & 0 & 0 & 0 \\
\hline $\begin{array}{l}\text { Chicken or turkey (including in } \\
\text { sandwiches, casseroles, salads, } \\
\text { and other mixed dishes) }\end{array}$ & 0 & 0 & 0 & 0 & 0 & 0 & 0 & $\mathrm{O}$ \\
\hline Gravy & 0 & 0 & 0 & 0 & 0 & 0 & 0 & 0 \\
\hline White bread or rolls & 0 & 0 & 0 & 0 & 0 & 0 & 0 & 0 \\
\hline $\begin{array}{l}\text { Dark bread or rolls (rye, whole } \\
\text { grain, whole wheat, pumpernickel) }\end{array}$ & 0 & 0 & 0 & O & $\mathrm{O}$ & 0 & 0 & 0 \\
\hline $\begin{array}{l}\text { French fries, home fries, or hash } \\
\text { brown potatoes }\end{array}$ & 0 & 0 & 0 & 0 & $\bigcirc$ & 0 & 0 & $\bigcirc$ \\
\hline $\begin{array}{l}\text { Other potatoes (baked, mashed, } \\
\text { boiled) }\end{array}$ & 0 & 0 & 0 & 0 & 0 & 0 & O & 0 \\
\hline $\begin{array}{l}\text { Lettuce salads (with or without } \\
\text { other vegetables) }\end{array}$ & 0 & 0 & 0 & 0 & 0 & 0 & 0 & 0 \\
\hline $\begin{array}{l}\text { Tomatoes, fresh (including in } \\
\text { salads) }\end{array}$ & 0 & 0 & 0 & 0 & 0 & 0 & O & 0 \\
\hline $\begin{array}{l}\text { Mayonnaise (including on } \\
\text { sandwiches, tuna, and potato salad) }\end{array}$ & O & 0 & 0 & 0 & 0 & 0 & 0 & 0 \\
\hline $\begin{array}{l}\text { Salad dressing for salads or } \\
\text { vegetables }\end{array}$ & 0 & 0 & 0 & 0 & 0 & 0 & 0 & 0 \\
\hline Broccoli & 0 & 0 & 0 & 0 & 0 & 0 & 0 & 0 \\
\hline Carrots & 0 & 0 & 0 & 0 & 0 & 0 & 0 & 0 \\
\hline $\begin{array}{l}\text { Other vegetables, such as corn, } \\
\text { peas, green beans }\end{array}$ & 0 & 0 & 0 & 0 & 0 & 0 & 0 & 0 \\
\hline $\begin{array}{l}\text { Real butter (including on bread } \\
\text { and vegetables) }\end{array}$ & 0 & 0 & 0 & 0 & 0 & 0 & O & 0 \\
\hline $\begin{array}{l}\text { Margarine (including on bread } \\
\text { and vegetables) }\end{array}$ & 0 & O & 0 & 0 & 0 & $O$ & 0 & 0 \\
\hline Cake & 0 & 0 & 0 & 0 & 0 & 0 & 0 & 0 \\
\hline Cookies or brownies & 0 & 0 & 0 & 0 & 0 & 0 & 0 & $\bigcirc$ \\
\hline Ice cream and milk shakes & 0 & O & 0 & 0 & 0 & 0 & 0 & 0 \\
\hline
\end{tabular}

\section{Appendix Figure 1:}

Adolescent food frequency questionnaire in the NIH-AARP Diet and Health Study

\section{HOW OFTEN (MARK ONLY ONE RESPONSE.)}

\begin{tabular}{|c|c|c|c|c|c|c|c|}
\hline \multirow{亠}{*}{} & $1-11$ & $1-3$ & $1-2$ & $3-4$ & $5-6$ & 1 & 2 \\
¿ & times & times & times & times & times & time & $\begin{array}{c}\text { or more } \\
\text { times }\end{array}$ \\
& $\begin{array}{c}\text { per } \\
\text { year }\end{array}$ & $\begin{array}{c}\text { per } \\
\text { month }\end{array}$ & $\begin{array}{c}\text { per } \\
\text { week }\end{array}$ & $\begin{array}{c}\text { per } \\
\text { week }\end{array}$ & $\begin{array}{c}\text { per } \\
\text { week }\end{array}$ & $\begin{array}{c}\text { per } \\
\text { day }\end{array}$ & $\begin{array}{c}\text { per } \\
\text { day }\end{array}$ \\
\hline
\end{tabular}



Cancer Causes Control. Author manuscript; available in PMC 2021 October 01. 


\section{Appendix Table 1:}

Relative risks (RRs) and 95\% confidence intervals (CIs) for dairy and calcium intake from 12-13 years of age in relation to more advanced prostate cancer (T4, N1, M1 or death from PCa) in the NIH-AARP Diet and Health Study, 1996-2011

\begin{tabular}{|c|c|c|c|c|c|c|c|}
\hline \multicolumn{7}{|c|}{ Intake categories } & \multirow{2}{*}{$\begin{array}{c}\text { P- } \\
\text { trend }\end{array}$} \\
\hline $\begin{array}{l}\text { Milk } \\
\text { intake }\end{array}$ & ş/week & 3-4/week & 5-6/week & 1/day & $\geq 2 /$ day & $\begin{array}{c}\text { Per } \\
\text { time/day }\end{array}$ & \\
\hline $\begin{array}{l}\text { No. of } \\
\text { cases/pyrs }\end{array}$ & $94 / 205,418$ & $113 / 237,861$ & $172 / 324,946$ & $230 / 435,864$ & $328 / 660,208$ & & \\
\hline $\begin{array}{l}\text { Age- } \\
\text { adjusted } \\
\text { RR }\end{array}$ & 1.00 & $\begin{array}{c}1.06(0.80- \\
1.39)\end{array}$ & $\begin{array}{c}1.17(0.91- \\
1.51)\end{array}$ & $\begin{array}{c}1.12(0.88- \\
1.42)\end{array}$ & $\begin{array}{c}1.09(0.87- \\
1.38)\end{array}$ & $\begin{array}{c}1.01 \\
(0.95- \\
1.06)\end{array}$ & 0.858 \\
\hline $\begin{array}{l}\text { Adjusted } \\
\text { RR }\end{array}$ & 1.00 & $\begin{array}{c}1.03(0.78- \\
1.35)\end{array}$ & $\begin{array}{c}1.12(0.87- \\
1.45)\end{array}$ & $\begin{array}{c}1.07(0.83- \\
1.37)\end{array}$ & $\begin{array}{c}0.99(0.76- \\
1.29)\end{array}$ & $\begin{array}{c}0.98 \\
(0.91- \\
1.05)\end{array}$ & 0.493 \\
\hline $\begin{array}{l}\text { Adjusted } \\
\mathrm{RR}^{2}\end{array}$ & 1.00 & $\begin{array}{c}1.04(0.79- \\
1.37)\end{array}$ & $\begin{array}{c}1.13(0.87- \\
1.47)\end{array}$ & $\begin{array}{c}1.07(0.83- \\
1.37)\end{array}$ & $\begin{array}{c}0.97(0.73- \\
1.29)\end{array}$ & $\begin{array}{c}0.97 \\
(0.89- \\
1.05)\end{array}$ & 0.389 \\
\hline $\begin{array}{l}\text { Cheese } \\
\text { intake }\end{array}$ & $\varsigma 3 /$ month & 1-2/week & 3-4/week & $\$ 5 /$ week & & $\begin{array}{c}\text { Per } \\
\text { time/day }\end{array}$ & \\
\hline $\begin{array}{l}\text { No. of } \\
\text { cases/pyrs }\end{array}$ & $412 / 747,283$ & $295 / 622,214$ & $178 / 339,181$ & $52 / 155,618$ & & & \\
\hline $\begin{array}{l}\text { Age- } \\
\text { adjusted } \\
\text { RR }\end{array}$ & 1.00 & $\begin{array}{c}0.91(0.78- \\
1.05)\end{array}$ & $\begin{array}{c}1.05(0.88- \\
1.25)\end{array}$ & $\begin{array}{c}0.68(0.51- \\
0.91)\end{array}$ & & $\begin{array}{c}0.79 \\
(0.58- \\
1.07)\end{array}$ & 0.133 \\
\hline $\begin{array}{l}\text { Adjusted } \\
\text { RR }\end{array}$ & 1.00 & $\begin{array}{c}0.89(0.77- \\
1.04)\end{array}$ & $\begin{array}{c}1.01(0.84- \\
1.22)\end{array}$ & $\begin{array}{c}0.66(0.49- \\
0.90)\end{array}$ & & $\begin{array}{c}0.75 \\
(0.53- \\
1.05)\end{array}$ & 0.096 \\
\hline $\begin{array}{l}\text { Adjusted } \\
\mathrm{RR}^{2}\end{array}$ & 1.00 & $\begin{array}{c}0.89(0.76- \\
1.04)\end{array}$ & $\begin{array}{c}1.00(0.83- \\
1.22)\end{array}$ & $\begin{array}{c}0.66(0.48- \\
0.90)\end{array}$ & & $\begin{array}{c}0.74 \\
(0.52- \\
1.05)\end{array}$ & 0.093 \\
\hline $\begin{array}{l}\text { Ice cream } \\
\text { intake }\end{array}$ & $\varsigma 3 /$ month & 1-2/week & 3-4/week & $\leq 5 /$ week & & $\begin{array}{c}\text { Per } \\
\text { time/day }\end{array}$ & \\
\hline $\begin{array}{l}\text { No. of } \\
\text { cases/pyrs }\end{array}$ & $473 / 853,048$ & $271 / 586,080$ & $140 / 282,632$ & $53 / 142,537$ & & & \\
\hline $\begin{array}{l}\text { Age- } \\
\text { adjusted } \\
\text { RR }\end{array}$ & 1.00 & $\begin{array}{c}0.92(0.79- \\
1.06)\end{array}$ & $\begin{array}{c}1.03(0.85- \\
1.24)\end{array}$ & $\begin{array}{c}0.77(0.58- \\
1.02)\end{array}$ & & $\begin{array}{c}0.83 \\
(0.61- \\
1.14)\end{array}$ & 0.246 \\
\hline $\begin{array}{l}\text { Adjusted } \\
\text { RR }\end{array}$ & 1.00 & $\begin{array}{c}0.89(0.76- \\
1.04)\end{array}$ & $\begin{array}{c}0.98(0.80- \\
1.20)\end{array}$ & $\begin{array}{c}0.72(0.53- \\
0.97)\end{array}$ & & $\begin{array}{c}0.75 \\
(0.53- \\
1.22)\end{array}$ & 0.109 \\
\hline $\begin{array}{l}\text { Adjusted } \\
\mathrm{RR}^{2}\end{array}$ & 1.00 & $\begin{array}{c}0.89(0.75- \\
1.04)\end{array}$ & $\begin{array}{c}0.98(0.79- \\
1.21)\end{array}$ & $\begin{array}{c}0.73(0.53- \\
1.00)\end{array}$ & & $\begin{array}{c}0.77 \\
(0.53- \\
1.11)\end{array}$ & 0.158 \\
\hline $\begin{array}{l}\text { Dairy } \\
\text { intake }\end{array}$ & $\leq 4 /$ week & 5-6/week & 1-2/day & 3/day & $\geq 4 /$ day & $\begin{array}{c}\text { Per } \\
\text { time/day }\end{array}$ & \\
\hline $\begin{array}{l}\text { No. of } \\
\text { cases/pyrs }\end{array}$ & $105 / 221,998$ & $116 / 203,857$ & $384 / 767,429$ & $190 / 360,819$ & $142 / 310,193$ & & \\
\hline
\end{tabular}

Cancer Causes Control. Author manuscript; available in PMC 2021 October 01. 


\begin{tabular}{|c|c|c|c|c|c|c|c|}
\hline \multicolumn{7}{|c|}{ Intake categories } & \multirow{2}{*}{$\frac{\begin{array}{c}\text { P- } \\
\text { trend }\end{array}}{0.886}$} \\
\hline $\begin{array}{l}\text { Age- } \\
\text { adjusted } \\
\text { RR }\end{array}$ & 1.00 & $\begin{array}{c}1.24(0.95- \\
1.61)\end{array}$ & $\begin{array}{c}1.10(0.89- \\
1.37)\end{array}$ & $\begin{array}{c}1.12(0.88- \\
1.42)\end{array}$ & $\begin{array}{c}1.06(0.83- \\
1.37)\end{array}$ & $\begin{array}{c}1.00 \\
(0.94- \\
1.06)\end{array}$ & \\
\hline $\begin{array}{l}\text { Adjusted } \\
\text { RR }\end{array}$ & 1.00 & $\begin{array}{c}1.20(0.92- \\
1.57)\end{array}$ & $\begin{array}{c}1.03(0.82- \\
1.30)\end{array}$ & $\begin{array}{c}0.99(0.75- \\
1.30)\end{array}$ & $\begin{array}{c}0.93(0.69- \\
1.27)\end{array}$ & $\begin{array}{c}0.96 \\
(0.89- \\
1.04)\end{array}$ & 0.275 \\
\hline $\begin{array}{l}\text { Adjusted } \\
\mathrm{RR}^{2}\end{array}$ & 1.00 & $\begin{array}{c}1.21(0.92- \\
1.58)\end{array}$ & $\begin{array}{c}1.04(0.82- \\
1.31)\end{array}$ & $\begin{array}{c}0.96(0.71- \\
1.30)\end{array}$ & $\begin{array}{c}0.91(0.66- \\
1.26)\end{array}$ & $\begin{array}{c}0.95 \\
(0.87- \\
1.03)\end{array}$ & 0.214 \\
\hline $\begin{array}{l}\text { Calcium } \\
\text { intake } \\
\text { (mg/1000 } \\
\text { kcal) }\end{array}$ & Q1 $(<318)$ & Q2 (318-386) & Q3 (386-487) & Q4 (487-627) & Q5 (>627) & $\underset{\text { quintile }}{\text { Per }}$ & \\
\hline $\begin{array}{l}\text { No. of } \\
\text { cases/pyrs }\end{array}$ & $173 / 372,645$ & $206 / 373,159$ & $181 / 372,942$ & $197 / 373,610$ & $180 / 371,940$ & & \\
\hline $\begin{array}{l}\text { Age- } \\
\text { adjusted } \\
\text { RR }\end{array}$ & 1.00 & $\begin{array}{c}1.18(0.97- \\
1.45)\end{array}$ & $\begin{array}{c}1.01(0.82- \\
1.24)\end{array}$ & $\begin{array}{c}1.11(0.90- \\
1.36)\end{array}$ & $\begin{array}{c}1.00(0.81- \\
1.23)\end{array}$ & $\begin{array}{c}0.92 \\
(0.61- \\
1.38)\end{array}$ & 0.675 \\
\hline $\begin{array}{l}\text { Adjusted } \\
\text { RR }\end{array}$ & 1.00 & $\begin{array}{c}1.18(0.96- \\
1.45)\end{array}$ & $\begin{array}{c}1.06(0.86- \\
1.31)\end{array}$ & $\begin{array}{c}1.17(0.94- \\
1.46)\end{array}$ & $\begin{array}{c}0.97(0.78- \\
1.21)\end{array}$ & $\begin{array}{c}0.88 \\
(0.58- \\
1.36)\end{array}$ & 0.574 \\
\hline $\begin{array}{l}\text { Adjusted } \\
\mathrm{RR}^{2}\end{array}$ & 1.00 & $\begin{array}{c}1.16(0.94- \\
1.43)\end{array}$ & $\begin{array}{c}1.03(0.83- \\
1.28)\end{array}$ & $\begin{array}{c}1.13(0.89- \\
1.43)\end{array}$ & $\begin{array}{c}0.92(0.71- \\
1.19)\end{array}$ & $\begin{array}{c}0.80 \\
(0.47- \\
1.36)\end{array}$ & 0.411 \\
\hline \multicolumn{8}{|c|}{$\begin{array}{l}\text { 1 Adjusted for age; adolescent energy intake; race; family history of prostate cancer; education; marital status; cigarette } \\
\text { smoking history; adult alcohol intake; adult waist circumference; body mass index at ages } 18,35,50 \text {, and baseline; } \\
\text { adolescent and adult physical activity; prostate-specific antigen and digital rectal examination screening history; diabetes } \\
\text { history; father's occupation; attained height; and adult intake of whole milk, cheese, ice cream, total high-fat dairy products } \\
\text { and calcium, as appropriate. } \\
2 \text { Adjusted for age; adolescent energy intake; race; family history of prostate cancer; education; marital status; cigarette } \\
\text { smoking history; adult alcohol intake; body mass index at ages } 18,35,50 \text {, and baseline; adolescent and adult physical } \\
\text { activity; prostate-specific antigen and digital rectal examination screening history; father's occupation; attained height; } \\
\text { adult intake of whole milk, cheese, ice cream, total high-fat dairy products and calcium, as appropriate; and adolescent } \\
\text { intake of grains, vegetables, fruits, potatoes, red meat, and sweets. }\end{array}$} \\
\hline
\end{tabular}

\section{REFERENCES}

1. Bray F, et al., Global cancer statistics 2018: GLOBOCAN estimates of incidence and mortality worldwide for 36 cancers in 185 countries. CA Cancer J Clin, 2018 68(6): p. 394-424. [PubMed: 30207593]

2. Brawley OW, Prostate cancer epidemiology in the United States. World J Urol, 2012 30(2): p. 195200. [PubMed: 22476558]

3. Sutcliffe S and Colditz GA, Prostate cancer: is it time to expand the research focus to early-life exposures? Nat Rev Cancer, 2013 13(3): p. 208-518. [PubMed: 23363989]

4. Angelsen A, et al., Pre- and postnatal testosterone administration induces proliferative epithelial lesions with neuroendocrine differentiation in the dorsal lobe of the rat prostate. Prostate, 1999 40(2): p. 65-75. [PubMed: 10386466]

5. Suttie A, et al., A grading scheme for the assessment ofproliferative lesions of the mouse prostate in the TRAMP model. Toxicol Pathol, 2003 31(1): p. 31-8. [PubMed: 12597447]

6. Suttie AW, et al., An investigation of the effects of late-onset dietary restriction on prostate cancer development in the TRAMP mouse. Toxicol Pathol, 2005 33(3): p. 386-97. [PubMed: 15805078] 
7. Diamandis EP and Yu H, Does prostate cancer start at puberty? J Clin Lab Anal, 1996 10(6): p. 468-9. [PubMed: 8951622]

8. Gu FL, Xia TL, and Kong XT, Preliminary study of the frequency of benign prostatic hyperplasia and prostatic cancer in China. Urology, 1994 44(5): p. 688-91. [PubMed: 7526525]

9. Sakr WA, et al., High grade prostatic intraepithelial neoplasia (HGPIN) and prostatic adenocarcinoma between the ages of20-69: an autopsy study of249 cases. In Vivo, 1994 8(3): p. 439-43. [PubMed: 7803731]

10. Sanchez-Chapado M, et al., Prevalence of prostate cancer and prostatic intraepithelial neoplasia in Caucasian Mediterranean males: an autopsy study. Prostate, 2003 54(3): p. 238-47. [PubMed: 12518329]

11. Yin M, et al., Prevalence of incidental prostate cancer in the general population: a study of healthy organ donors. J Urol, 2008 179(3): p. 892-5; discussion 895. [PubMed: 18207193]

12. Jackson MA, et al., Factors involved in the high incidence of prostatic cancer among American blacks. Prog Clin Biol Res, 1981 53: p. 111-32. [PubMed: 7465581]

13. Sakr WA, et al., The frequency of carcinoma and intraepithelial neoplasia of the prostate in young male patients. J Urol, 1993 150(2 Pt 1): p. 379-85. [PubMed: 8326560]

14. Shiraishi T, et al., The frequency of latent prostatic carcinoma in young males: the Japanese experience. In Vivo, 1994 8(3): p. 445-7. [PubMed: 7803732]

15. Guileyardo JM, et al., Prevalence of latent prostate carcinoma in two U.S. populations. J Natl Cancer Inst, 1980 65(2): p. 311-6. [PubMed: 6931251]

16. Jahn JL, Giovannucci EL, and Stampfer MJ, The high prevalence of undiagnosed prostate cancer at autopsy: implications for epidemiology and treatment ofprostate cancer in the Prostate-specific Antigen-era. Int J Cancer, 2015 137(12): p. 2795-802. [PubMed: 25557753]

17. Howlader N, et al., SEER Cancer Statistics Review, 1975---2009 (Vintage 2009 Populations). National Cancer Institute. 20122013.

18. Clarke MA and Joshu CE, Early Life Exposures and Adult Cancer Risk. Epidemiol Rev, 2017 39(1): p. 11-27. [PubMed: 28407101]

19. Colditz GA, Bohlke K, and Berkey CS, Breast cancer risk accumulation starts early: prevention must also. Breast Cancer Res Treat, 2014 145(3): p. 567-79. [PubMed: 24820413]

20. Mahabir S, Association between diet during preadolescence and adolescence and risk for breast cancer during adulthood. J Adolesc Health, 2013 52(5 Suppl): p. S30-5. [PubMed: 23298994]

21. Gronberg H, Prostate cancer epidemiology. Lancet, 2003 361(9360): p. 859-64. [PubMed: 12642065]

22. Aune D, et al., Dairy products, calcium, and prostate cancer risk: a systematic review and metaanalysis of cohort studies. Am J Clin Nutr, 2015 101(1): p. 87-117. [PubMed: 25527754]

23. Lopez-Plaza B, et al., Milk and Dairy Product Consumption and Prostate Cancer Risk and Mortality: An Overview of Systematic Reviews and Meta-analyses. Adv Nutr, 2019 10(suppl_2): p. S212-s223. [PubMed: 31089741]

24. Harrison S, et al., Does milk intake promote prostate cancer initiation or progression via effects on insulin-like growth factors (IGFs)? A systematic review and meta-analysis. Cancer Causes Control, 2017 28(6): p. 497-528. [PubMed: 28361446]

25 . Lu W, et al., Dairy products intake and cancer mortality risk: a meta-analysis of 11 populationbased cohort studies. Nutr J, 2016 15(1): p. 91. [PubMed: 27765039]

26. Travis RC, et al., A Meta-analysis of Individual Participant Data Reveals an Association between Circulating Levels of IGF-I and Prostate Cancer Risk. Cancer Res, 2016 76(8): p. 2288-2300. [PubMed: 26921328]

27. Villamor E and Jansen EC, Nutritional Determinants of the Timing of Puberty. Annu Rev Public Health, 2016 37: p. 33-46. [PubMed: 26789387]

28. Gunnell D, et al., Height, leg length, and cancer risk: a systematic review. Epidemiol Rev, 2001 23(2): p. 313-42. [PubMed: 12192740]

29. Cook MB, et al., Childhood height and birth weight in relation to future prostate cancer risk: a cohort study based on the copenhagen school health records register. Cancer Epidemiol Biomarkers Prev, 2013 22(12): p. 2232-40. [PubMed: 24089459] 
30. Aarestrup J, et al., Childhood height increases the risk of prostate cancer mortality. Eur J Cancer, 2015 51(10): p. 1340-5. [PubMed: 25899985]

31. Bonilla C, et al., Pubertal development and prostate cancer risk: Mendelian randomization study in a population-based cohort. BMC Med, 2016 14: p. 66. [PubMed: 27044414]

32. Zuccolo L, et al., Height and prostate cancer risk: a large nested case-control study (ProtecT) and meta-analysis. Cancer Epidemiol Biomarkers Prev, 2008 17(9): p. 2325-36. [PubMed: 18768501]

33. Adult height and the risk of cause-specific death and vascular morbidity in 1 million people: individual participant meta-analysis. Int J Epidemiol, 2012 41(5): p. 1419-33. [PubMed: 22825588]

34. Berkey CS, et al., Dairy consumption and female height growth: prospective cohort study. Cancer Epidemiol Biomarkers Prev, 2009 18(6): p. 1881-7. [PubMed: 19505921]

35. Wiley AS, Does milk make children grow? Relationships between milk consumption and height in NHANES1999-2002. Am J Hum Biol, 2005 17(4): p. 425-41. [PubMed: 15981182]

36. Robinson WR, Poole C, and Godley PA, Systematic review of prostate cancer's association with body size in childhood and young adulthood. Cancer Causes Control, 2008 19(8): p. 793-803. [PubMed: 18347923]

37. Eide MG, et al., Size at birth and gestational age as predictors of adult height and weight. Epidemiology, 2005 16(2): p. 175-81. [PubMed: 15703531]

38. Gunther AL, et al., Dietary protein intake throughout childhood is associated with the timing of puberty. J Nutr, 2010 140(3): p. 565-71. [PubMed: 20042466]

39. Torfadottir JE, et al., Milk intake in early life and risk of advanced prostate cancer. Am J Epidemiol, 2012 175(2): p. 144-53. [PubMed: 22190107]

40. Andersson SO, et al., Early life riskfactors for prostate cancer: a population-based case-control study in Sweden. Cancer Epidemiol Biomarkers Prev, 1995 4(3): p. 187-92. [PubMed: 7606192]

41. van der Pols JC, et al., Childhood dairy intake and adult cancer risk: 65-y follow-up of the Boyd Orr cohort. Am J Clin Nutr, 2007 86(6): p. 1722-9. [PubMed: 18065592]

42. Schatzkin A, et al., Design and serendipity in establishing a large cohort with wide dietary intake distributions : the National Institutes of Health-American Association of Retired Persons Diet and Health Study. Am J Epidemiol, 2001 154(12): p. 1119-25. [PubMed: 11744517]

43. Munger KL, et al., Dietary intake of vitamin D during adolescence and risk of multiple sclerosis. J Neurol, 2011 258(3): p. 479-85. [PubMed: 20945071]

44. Ruder EH, et al., Adolescent and mid-life diet: risk of colorectal cancer in the NIH-AARP Diet and Health Study. Am J Clin Nutr, 2011 94(6): p. 1607-19. [PubMed: 22071715]

45. Rosenblatt KA, Wicklund KG, and Stanford JL, Sexual factors and the risk of prostate cancer. Am J Epidemiol, 2001 153(12): p. 1152-8. [PubMed: 11415949]

46. Maruti SS, et al., Adult recall of adolescent diet: reproducibility and comparison with maternal reporting. Am J Epidemiol, 2005 161(1): p. 89-97. [PubMed: 15615919]

47. Maruti SS, et al., Validation of adolescent diet recalled by adults. Epidemiology, 2006 17(2): p. 226-9. [PubMed: 16477265]

48. Potischman N, et al., Diet during adolescence and risk of breast cancer among young women. J Natl Cancer Inst, 1998 90(3): p. 226-33. [PubMed: 9462680]

49. Dwyer JT, et al., Memory offood intake in the distant past. Am J Epidemiol, 1989 130(5): p. 103346. [PubMed: 2816890]

50. Chavarro JE, et al., Validity of adolescent diet recall 48 years later. Am J Epidemiol, 2009 170(12): p. 1563-70. [PubMed: 19923106]

51. Wolk A, et al., Reliability of retrospective information on diet 20 years ago and consistency of independent measurements of remote adolescent diet. Nutr Cancer, 1997 29(3): p. 234-41. [PubMed: 9457745]

52. McCullough ML and Giovannucci EL, Diet and cancer prevention. Oncogene, 2004 23(38): p. 6349-64. [PubMed: 15322510]

53. Bylsma LC and Alexander DD, A review and meta-analysis of prospective studies of red and processed meat, meat cooking methods, heme iron, heterocyclic amines and prostate cancer. Nutr J, 2015 14: p. 125. [PubMed: 26689289] 
54. Kissinger DG and Sanchez A, The association of dietary factors with the age of menarche. Nutrition Research, 1987 7: p. 471-479.

55. de Ridder CM, et al., Dietary habits, sexual maturation, and plasma hormones in pubertal girls: a longitudinal study. Am J Clin Nutr, 1991 54(5): p. 805-13. [PubMed: 1951150]

56. Merzenich H, Boeing $\mathrm{H}$, and Wahrendorf J, Dietary fat and sports activity as determinants for age at menarche. Am J Epidemiol, 1993 138(4): p. 217-24. [PubMed: 8356963]

57. Berkey CS, et al., Relation of childhood diet and body size to menarche and adolescent growth in girls. Am J Epidemiol, 2000 152(5): p. 446-52. [PubMed: 10981459]

58. Cheng G, et al., Diet quality in childhood is prospectively associated with the timing of puberty but not with body composition at puberty onset. J Nutr, 2010 140(1): p. 95-102. [PubMed: 19923386]

59. Rogers IS, et al., Diet throughout childhood and age at menarche in a contemporary cohort of British girls. Public Health Nutr, 2010 13(12): p. 2052-63. [PubMed: 20529402]

60. Alimujiang A, et al., Childhood diet and growth in boys in relation to timing of puberty and adult height: the Longitudinal Studies of Child Health and Development. Cancer Causes Control, 2018 29(10): p. 915-926. [PubMed: 30109531]

61. Madathil S, et al., Disadvantageous Socioeconomic Position at Specific Life Periods May Contribute to Prostate Cancer Risk and Aggressiveness. Front Oncol, 2018 8: p. 515. [PubMed: 30498692]

62. de Kok IM, et al., Childhood social class and cancer incidence: results of the globe study. Soc Sci Med, 2008 66(5): p. 1131-9. [PubMed: 18164526]

63. Nicolau B, et al., Shared social mechanisms underlying the risk of nine cancers: A life course study. Int J Cancer, 2019 144(1): p. 59-67. [PubMed: 29981162]

64. Casas F, et al., Adapted ice cream as a nutritional supplement in cancer patients: impact on quality of life and nutritional status. Clin Transl Oncol, 2012 14(1): p. 66-72. [PubMed: 22262721]

65. Gijsbers L, et al., Consumption of dairy foods and diabetes incidence: a dose-response metaanalysis of observational studies. Am J Clin Nutr, 2016 103(4): p. 1111-24. [PubMed: 26912494] 
Table 1:

Baseline demographic, lifestyle, and medical characteristics of men by adolescent total dairy and calcium intake, NIH-AARP Diet and Health Study, 1996-2011

\begin{tabular}{|c|c|c|c|c|c|c|}
\hline & \multicolumn{3}{|c|}{$\begin{array}{c}\begin{array}{c}\text { Frequency of energy-adjusted total dairy } \\
\text { intake }\end{array} \\
\end{array}$} & \multicolumn{3}{|c|}{$\begin{array}{c}\text { Quintile of energy-adjusted calcium intake (mg/ } \\
1000 \mathrm{kcal})\end{array}$} \\
\hline & $\leq 4 /$ week & $1-2 /$ day & $\geq 4 /$ day & Q1 $(<318)$ & Q3 (386-487) & Q5 (>627) \\
\hline No. & 19,559 & 66,803 & 26,829 & 32,563 & 32,564 & 32,563 \\
\hline \multicolumn{7}{|l|}{ Demographic characteristics: } \\
\hline Age (mean, years) & 61.8 & 61.7 & 61.6 & 61.6 & 62.0 & 62.1 \\
\hline Non-Hispanic White (\%) & 90.9 & 94.2 & 96.8 & 92.5 & 94.3 & 95.9 \\
\hline \multicolumn{7}{|l|}{ Education $(\%)^{1}$} \\
\hline 12 years or less & 25.0 & 18.1 & 12.9 & 22.2 & 18.6 & 15.9 \\
\hline Post-high school or some college & 32.7 & 30.7 & 28.8 & 32.7 & 31.1 & 30.7 \\
\hline College graduate & 19.7 & 23.4 & 25.6 & 21.4 & 23.0 & 24.2 \\
\hline Post graduate & 19.7 & 25.7 & 31.3 & 21.2 & 25.3 & 27.6 \\
\hline Married (\%) & 84.0 & 85.2 & 86.8 & 84.3 & 85.9 & 86.6 \\
\hline
\end{tabular}

Adolescent characteristics:

Father's occupation (\%)

Professional or technical (e.g., doctor, lawyer)

Managerial (e.g., plant manage

CEO)

3.9

5.8

8.4

4.2

6.0

7.2

Other non-manual (e.g., bank
teller)

$\begin{array}{ll}6.3 & 9.7\end{array}$

12.2

8.2

9.5

10.3

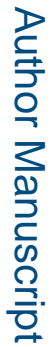

Manual (e.g., carpenter, electrician)

18.5

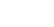

11.9

7.9

9.6

10.6

Other manual (e.g., farm laborer)

18.5

18.0

18.5

18.6

17.7

Unknown

43.4

16.4

14.2

18.9

16.9

16.6

Participants' age in 1945 (years, \%)

$\begin{array}{rr}<12 & 47.5 \\ 12 \text { to } 18 & 45.5 \\ >18 & 7.0\end{array}$

47.6
45.5
6.9

\section{0}

42.3

39.5

37.6

$$
\text { ram }
$$

Body mass index at age $18\left(\mathrm{~kg} / \mathrm{m}^{2}\right)$

21.8

21.8

44.2

49.3

45.2

44.9

Physical activity $\geq 5$ times/week

49.4

49.6

44.4

47.0

47.3

6.3

7.9

7.9

(\%)

Mean intake of:

\begin{tabular}{|c|c|c|c|c|c|c|}
\hline Milk (times consumed/d) & 0.19 & 0.86 & 3.03 & 0.43 & 1.10 & 2.87 \\
\hline Cheese (times consumed/d) & 0.17 & 0.29 & 0.41 & 0.23 & 0.25 & 0.21 \\
\hline Ice cream (times consumed/d) & 0.18 & 0.27 & 0.32 & 0.24 & 0.22 & 0.18 \\
\hline Calcium $(\mathrm{mg} / 1000 \mathrm{kcal})$ & 195 & 377 & 708 & 262 & 430 & 744 \\
\hline Grains (times consumed/d) & 1.25 & 1.11 & 1.05 & 1.07 & 1.05 & 1.11 \\
\hline Fruits (times consumed/d) & 0.85 & 0.99 & 0.95 & 0.79 & 0.91 & 0.86 \\
\hline
\end{tabular}

Cancer Causes Control. Author manuscript; available in PMC 2021 October 01. 


\begin{tabular}{|c|c|c|c|c|c|c|}
\hline & \multicolumn{3}{|c|}{$\begin{array}{c}\text { Frequency of energy-adjusted total dairy } \\
\text { intake }\end{array}$} & \multicolumn{3}{|c|}{$\begin{array}{l}\text { Quintile of energy-adjusted calcium intake (mg } \\
1000 \mathrm{kcal})\end{array}$} \\
\hline & 44/week & $1-2 /$ day & $\geq 4 /$ day & Q1 (<318) & Q3 (386-487) & Q5 (>627) \\
\hline Vegetables (times consumed/d) & 1.82 & 1.66 & 1.34 & 1.59 & 1.52 & 1.40 \\
\hline $\begin{array}{r}\text { Red and processed meat (times } \\
\text { consumed/d) }\end{array}$ & 1.43 & 1.35 & 0.98 & 1.48 & 1.09 & 0.91 \\
\hline Total fats (\% of kcal) & 49 & 50 & 49 & 51 & 49 & 49 \\
\hline \multicolumn{7}{|l|}{$\begin{array}{l}\text { Adult (baseline) lifestyle and } \\
\text { medical characteristics: }\end{array}$} \\
\hline Body mass index $\left(\mathrm{kg} / \mathrm{m}^{2}\right)$ & 27.6 & 27.2 & 26.8 & 27.5 & 27.1 & 26.8 \\
\hline Height (meters) & 1.78 & 1.78 & 1.79 & 1.78 & 1.78 & 1.79 \\
\hline $\begin{array}{l}\text { Physical activity } \geq 5 \text { times/ week } \\
(\%)\end{array}$ & 21.8 & 23.0 & 22.4 & 21.7 & 22.2 & 22.2 \\
\hline \multicolumn{7}{|l|}{ Mean intake of: } \\
\hline Dairy (g/day) & 40.8 & 43.1 & 51.3 & 41.1 & 44.7 & 54.9 \\
\hline Calcium (mg/1000 kcal) & 364 & 401 & 451 & 373 & 411 & 457 \\
\hline \multicolumn{7}{|l|}{ Family history of prostate cancer $(\%)$} \\
\hline Yes & 9.2 & 9.5 & 9.7 & 9.2 & 9.6 & 9.9 \\
\hline Unknown & 21.2 & 19.4 & 17.8 & 20.6 & 19.4 & 18.3 \\
\hline Never smoker (\%) & 26.4 & 30.6 & 32.4 & 27.4 & 30.9 & 30.8 \\
\hline Diabetes mellitus status (\%) & 11.7 & 10.0 & 7.4 & 11.0 & 9.5 & 8.4 \\
\hline \multicolumn{7}{|l|}{ History of PSA screening (\%): } \\
\hline Never & 21.2 & 20.3 & 20.3 & 21.0 & 20.4 & 20.3 \\
\hline Once & 24.8 & 24.2 & 23.6 & 24.6 & 23.7 & 23.9 \\
\hline More than once & 45.7 & 48.0 & 48.8 & 46.6 & 48.2 & 48.4 \\
\hline Unknown & 8.3 & 7.5 & 7.3 & 7.9 & 7.7 & 7.3 \\
\hline \multicolumn{7}{|l|}{ History of DRE screening (\%) } \\
\hline Never & 14.6 & 13.3 & 13.6 & 14.3 & 13.6 & 13.8 \\
\hline Once & 27.2 & 26.6 & 24.8 & 27.1 & 26.2 & 25.7 \\
\hline More than once & 55.6 & 57.6 & 59.5 & 56.0 & 57.6 & 58.4 \\
\hline Unknown & 2.7 & 2.5 & 2.1 & 2.7 & 2.6 & 2.1 \\
\hline
\end{tabular}

$\mathrm{DRE}=$ digital rectal examination; PSA=prostate-specific antigen.

${ }^{1}$ Some percentages may not sum to $100 \%$ because of missing values. 
Table 2:

Relative risks (RRs) and 95\% confidence intervals (CIs) for dairy and calcium intake from 12-13 years of age in relation to total prostate cancer in the NIH-AARP Diet and Health Study, 1996-2011

\begin{tabular}{|c|c|c|c|c|c|c|c|}
\hline & & & Intake categories & & & & P-trend \\
\hline Milk intake & ㄴ/week & 3-4/week & 5-6/week & 1/day & $\geq 2 /$ day & Per time/day & \\
\hline No. of cases/pyrs & $1,803 / 205,418$ & $2,287 / 237,861$ & $3,110 / 324,946$ & $4,108 / 435,864$ & $6,421 / 660,208$ & & \\
\hline Age-adjusted RR & 1.00 & $1.10(1.04-1.17)$ & $1.10(1.03-1.16)$ & $1.06(1.00-1.12)$ & $1.11(1.05-1.17)$ & $\begin{array}{c}1.02(1.01- \\
1.03)\end{array}$ & 0.004 \\
\hline Adjusted RR ${ }^{1}$ & 1.00 & $1.08(1.01-1.14)$ & $1.06(1.00-1.13)$ & $1.03(0.97-1.09)$ & $1.08(1.02-1.15)$ & $\begin{array}{c}1.02(1.00- \\
1.03)\end{array}$ & 0.036 \\
\hline Adjusted $\mathrm{RR}^{2}$ & 1.00 & $1.07(1.01-1.14)$ & $1.05(0.99-1.12)$ & $1.02(0.96-1.08)$ & $1.06(0.99-1.14)$ & $\begin{array}{c}1.01(0.99- \\
1.03)\end{array}$ & 0.211 \\
\hline Cheese intake & $\varsigma 3 /$ month & 1-2/week & 3-4/week & $\leq 5 /$ week & & Per time/day & \\
\hline No. of cases/pyrs & $7,174 / 747,283$ & $6,007 / 622,214$ & $3,177 / 339,181$ & $1,371 / 155,618$ & & & \\
\hline Age-adjusted RR & 1.00 & $1.03(0.99-1.06)$ & $1.01(0.97-1.06)$ & $0.97(0.91-1.02)$ & & $\begin{array}{c}0.97(0.91- \\
1.04)\end{array}$ & 0.461 \\
\hline Adjusted RR ${ }^{1}$ & 1.00 & $1.01(0.98-1.05)$ & $1.00(0.95-1.04)$ & $0.97(0.91-1.03)$ & & $\begin{array}{c}0.96(0.89- \\
1.04)\end{array}$ & 0.355 \\
\hline Adjusted $\mathrm{RR}^{2}$ & 1.00 & $1.01(0.98-1.05)$ & $1.00(0.96-1.05)$ & $0.98(0.92-1.04)$ & & $\begin{array}{l}0.98(0.91- \\
1.06)\end{array}$ & 0.640 \\
\hline Ice cream intake & $\varsigma 3 /$ month & 1-2/week & 3-4/week & $\succeq$ /week & & Per time/day & \\
\hline No. of cases/pyrs & $8,226 / 853,048$ & $5,654 / 586,080$ & $2,603 / 282,632$ & $1,246 / 142,537$ & & & \\
\hline Age-adjusted RR & 1.00 & $1.04(1.01-1.08)$ & $1.01(0.97-1.06)$ & $0.96(0.91-1.02)$ & & $\begin{array}{c}0.97(0.91- \\
1.04)\end{array}$ & 0.417 \\
\hline Adjusted RR ${ }^{1}$ & 1.00 & $1.01(0.98-1.05)$ & $0.98(0.94-1.03)$ & $0.95(0.89-1.01)$ & & $\begin{array}{c}0.94(0.87- \\
1.01)\end{array}$ & 0.110 \\
\hline Adjusted $\mathrm{RR}^{2}$ & 1.00 & $1.01(0.97-1.05)$ & $0.98(0.93-1.02)$ & $0.94(0.88-1.00)$ & & $\begin{array}{c}0.92(0.84- \\
1.00)\end{array}$ & 0.046 \\
\hline Dairy intake & $\leq 4 /$ week & 5-6/week & 1-2/day & 3/day & $\geq 4 /$ day & Per time/day & \\
\hline No. of cases/pyrs & $2,013 / 221,998$ & $1,934 / 203,857$ & $7,251 / 767,429$ & $3,653 / 360,819$ & $2,878 / 310,193$ & & \\
\hline Age-adjusted RR & 1.00 & $1.06(0.99-1.13)$ & $1.06(1.01-1.11)$ & $1.12(1.06-1.18)$ & $1.06(1.00-1.13)$ & $\begin{array}{c}1.02(1.00- \\
1.03)\end{array}$ & 0.006 \\
\hline Adjusted RR ${ }^{1}$ & 1.00 & $1.05(0.98-1.11)$ & $1.05(0.99-1.10)$ & $1.11(1.04-1.18)$ & $1.06(0.99-1.14)$ & $\begin{array}{c}1.02(1.00- \\
1.04)\end{array}$ & 0.025 \\
\hline Adjusted $\mathrm{RR}^{2}$ & 1.00 & $1.04(0.98-1.11)$ & $1.04(0.98-1.10)$ & $1.10(1.03-1.18)$ & $1.04(0.97-1.12)$ & $\begin{array}{c}1.01(0.99- \\
1.03)\end{array}$ & 0.177 \\
\hline $\begin{array}{l}\text { Calcium intake } \\
(\mathrm{mg} / 1000 \mathrm{kcal})\end{array}$ & Q1 (<318) & Q2 (318-386) & Q3 (386-487) & Q4 (487-627) & Q5 (>627) & Per quintile & \\
\hline No. of cases/pyrs & $3,334 / 372,645$ & $3,548 / 373,159$ & $3,599 / 372,942$ & $3,478 / 373,610$ & $3,770 / 371,940$ & & \\
\hline Age-adjusted RR & 1.00 & $1.06(1.01-1.11)$ & $1.06(1.01-1.11)$ & $1.03(0.98-1.08)$ & $1.11(1.06-1.17)$ & $\begin{array}{c}1.18(1.08- \\
1.30)\end{array}$ & $<0.001$ \\
\hline Adjusted RR ${ }^{1}$ & 1.00 & $1.05(1.00-1.10)$ & $1.05(1.00-1.10)$ & $1.01(0.96-1.07)$ & $1.09(1.03-1.14)$ & $\begin{array}{c}1.13(1.02- \\
1.25)\end{array}$ & 0.016 \\
\hline
\end{tabular}

Cancer Causes Control. Author manuscript; available in PMC 2021 October 01. 


\begin{tabular}{|c|c|c|c|c|c|c|c|}
\hline & & & Intake categories & & & & P-trenc \\
\hline Adjusted $\mathrm{RR}^{2}$ & 1.00 & $1.04(0.99-1.09)$ & $1.04(0.99-1.09)$ & $1.00(0.95-1.06)$ & $1.08(1.01-1.14)$ & $\begin{array}{c}1.11(0.98- \\
1.25)\end{array}$ & 0.098 \\
\hline
\end{tabular}

${ }^{1} \mathrm{~A}$ alcohol intake; adult waist circumference; body mass index at ages 18, 35, 50, and baseline; adolescent and adult physical activity; prostate-specific antigen and digital rectal examination screening history; diabetes history; father's occupation; attained height; and adult intake of whole milk, cheese, ice cream, total high-fat dairy products and calcium, as appropriate.

${ }^{2}$ Adjusted for age; adolescent energy intake; race; family history of prostate cancer; education; marital status; cigarette smoking history; adult alcohol intake; body mass index at ages 18,35, 50, and baseline; adolescent and adult physical activity; prostate-specific antigen and digital rectal examination screening history; father's occupation; attained height; adult intake of whole milk, cheese, ice cream, total high-fat dairy products and calcium, as appropriate; and adolescent intake of grains, vegetables, fruits, potatoes, red meat, and sweets. 
Table 3:

Relative risks (RRs) and 95\% confidence intervals (CIs) for dairy and calcium intake from 12-13 years of age in relation to advanced prostate cancer (T3-T4, N1, M1 or death from PCa) in the NIH-AARP Diet and Health Study, 1996-2011

\begin{tabular}{|c|c|c|c|c|c|c|c|}
\hline \multicolumn{7}{|c|}{ Intake categories } & \multirow{2}{*}{$\begin{array}{c}\text { P- } \\
\text { trend }\end{array}$} \\
\hline Milk intake & s//week & 3-4/week & 5-6/week & 1/day & $\geq 2 /$ day & Per time/day & \\
\hline No. of cases/pyrs & $230 / 205,418$ & $286 / 237,861$ & $413 / 324,946$ & $535 / 435,864$ & $884 / 660,208$ & & \\
\hline Age-adjusted RR & 1.00 & $1.08(0.91-1.28)$ & $1.14(0.97-1.34)$ & $1.09(0.93-1.27)$ & $1.20(1.04-1.39)$ & $\begin{array}{c}1.05(1.01- \\
1.08)\end{array}$ & 0.011 \\
\hline Adjusted RR ${ }^{1}$ & 1.00 & $1.04(0.87-1.24)$ & $1.07(0.91-1.26)$ & $1.03(0.87-1.20)$ & $1.12(0.94-1.32)$ & $\begin{array}{c}1.03(0.99- \\
1.08)\end{array}$ & 0.148 \\
\hline Adjusted $\mathrm{RR}^{2}$ & 1.00 & $1.05(0.88-1.25)$ & $1.07(0.91-1.26)$ & $1.00(0.85-1.18)$ & $1.03(0.86-1.24)$ & $\begin{array}{c}1.00(0.95- \\
1.06)\end{array}$ & 0.931 \\
\hline Cheese intake & $\varsigma 3 /$ month & 1-2/week & 3-4/week & $\square /$ week & & Per time/day & \\
\hline No. of cases/pyrs & $956 / 747,283$ & $802 / 622,214$ & $436 / 339,181$ & $154 / 155,618$ & & & \\
\hline Age-adjusted RR & 1.00 & $1.02(0.93-1.12)$ & $1.03(0.92-1.15)$ & $0.80(0.67-0.94)$ & & $\begin{array}{c}0.84(0.70- \\
1.02)\end{array}$ & 0.074 \\
\hline Adjusted RR ${ }^{1}$ & 1.00 & $0.98(0.89-1.08)$ & $0.97(0.86-1.09)$ & $0.76(0.63-0.91)$ & & $\begin{array}{c}0.77(0.62- \\
0.95)\end{array}$ & 0.015 \\
\hline Adjusted $\mathrm{RR}^{2}$ & 1.00 & $0.98(0.89-1.08)$ & $0.99(0.87-1.12)$ & $0.78(0.65-0.94)$ & & $\begin{array}{c}0.80(0.64- \\
0.99)\end{array}$ & 0.043 \\
\hline Ice cream intake & $\varsigma 3 /$ month & 1-2/week & 3-4/week & $\triangle 5 /$ week & & Per time/day & \\
\hline No. of cases/pyrs & $1,107 / 853,048$ & $736 / 586,080$ & $359 / 282,632$ & $146 / 142,537$ & & & \\
\hline Age-adjusted RR & 1.00 & $0.99(0.90-1.09)$ & $1.01(0.90-1.14)$ & $0.81(0.69-0.97)$ & & $\begin{array}{c}0.85(0.70- \\
1.03)\end{array}$ & 0.096 \\
\hline Adjusted RR ${ }^{1}$ & 1.00 & $0.94(0.86-1.04)$ & $0.94(0.83-1.07)$ & $0.77(0.64-0.93)$ & & $\begin{array}{c}0.77(0.62- \\
0.95)\end{array}$ & 0.017 \\
\hline Adjusted $\mathrm{RR}^{2}$ & 1.00 & $0.96(0.87-1.07)$ & $0.99(0.86-1.13)$ & $0.83(0.68-1.01)$ & & $\begin{array}{c}0.85(0.67- \\
1.06)\end{array}$ & 0.153 \\
\hline Dairy intake & 4/week & 5-6/week & 1-2/day & 3/day & $\geq 4 /$ day & Per time/day & \\
\hline No. of cases/pyrs & $264 / 221,998$ & $269 / 203,857$ & $918 / 767,429$ & $507 / 360,819$ & $390 / 310,193$ & & \\
\hline Age-adjusted RR & 1.00 & $1.12(0.94-1.32)$ & $1.02(0.89-1.17)$ & $1.18(1.02-1.37)$ & $1.08(0.92-1.26)$ & $\begin{array}{c}1.03(0.99- \\
1.07)\end{array}$ & 0.113 \\
\hline Adjusted RR ${ }^{1}$ & 1.00 & $1.07(0.90-1.27)$ & $0.94(0.81-1.09)$ & $1.06(0.90-1.27)$ & $0.99(0.82-1.20)$ & $\begin{array}{c}1.01(0.96- \\
1.06)\end{array}$ & 0.682 \\
\hline Adjusted RR 2 & 1.00 & $1.08(0.91-1.28)$ & $0.94(0.81-1.09)$ & $0.99(0.82-1.20)$ & $0.93(0.76-1.14)$ & $\begin{array}{c}0.98(0.93- \\
1.03)\end{array}$ & 0.434 \\
\hline $\begin{array}{l}\text { Calcium intake } \\
(\mathrm{mg} / 1000 \mathrm{kcal})\end{array}$ & Q1 $(<318)$ & Q2 (318-386) & Q3 (386-487) & Q4 (487-627) & Q5 (>627) & Per quintile & \\
\hline No. of cases/pyrs & $421 / 372,645$ & $476 / 373,159$ & $446 / 372,942$ & $474 / 373,610$ & $531 / 371,940$ & & \\
\hline Age-adjusted RR & 1.00 & $1.13(0.99-1.29)$ & $1.05(0.92-1.20)$ & $1.12(0.98-1.27)$ & $1.25(1.10-1.42)$ & $\begin{array}{c}1.53(1.18- \\
1.97)\end{array}$ & 0.001 \\
\hline
\end{tabular}

Cancer Causes Control. Author manuscript; available in PMC 2021 October 01. 


\begin{tabular}{|c|c|c|c|c|c|c|c|}
\hline \multicolumn{7}{|c|}{ Intake categories } & \multirow{2}{*}{$\begin{array}{c}\begin{array}{c}\mathbf{P}- \\
\text { trend }\end{array} \\
0.017\end{array}$} \\
\hline Adjusted RR ${ }^{1}$ & 1.00 & $1.10(0.97-1.26)$ & $1.05(0.91-1.20)$ & $1.13(0.98-1.30)$ & $1.19(1.04-1.36)$ & $\begin{array}{c}1.39(1.06- \\
1.82)\end{array}$ & \\
\hline Adjusted $\mathrm{RR}^{2}$ & 1.00 & $1.07(0.94-1.22)$ & $1.01(0.88-1.16)$ & $1.05(0.90-1.23)$ & $1.10(0.94-1.29)$ & $\begin{array}{c}1.17(0.84- \\
1.63)\end{array}$ & 0.352 \\
\hline
\end{tabular}

${ }^{1}$ Adjusted RR2 1.001 .07 (0.94-1.22) 1.01 (0.88-1.16) 1.05 (0.90-1.23) $1.10(0.94-1.29) 1.17$ (0.84-1.63) 0.3521 Adjusted for age; adolescent energy intake; race; family history of prostate cancer; education; marital status; cigarette smoking history; adult alcohol intake; adult waist circumference; body mass index at ages 18,35, 50, and baseline; adolescent and adult physical activity; prostate-specific antigen and digital rectal examination screening history; diabetes history; father's occupation; attained height; and adult intake of whole milk, cheese, ice cream, total highfat dairy products and calcium, as appropriate.

2 Adjusted for age; adolescent energy intake; race; family history of prostate cancer; education; marital status; cigarette smoking history; adult alcohol intake; body mass index at ages 18,35, 50, and baseline; adolescent and adult physical activity; prostate-specific antigen and digital rectal examination screening history; father's occupation; attained height; adult intake of whole milk, cheese, ice cream, total high-fat dairy products and calcium, as appropriate; and adolescent intake of grains, vegetables, fruits, potatoes, red meat, and sweets. 
Table 4:

Relative risks (RRs) and 95\% confidence intervals (CIs) for dairy and calcium intake from 12-13 years of age in relation to fatal prostate cancer in the NIH-AARP Diet and Health Study, 1996-2011

\begin{tabular}{|c|c|c|c|c|c|c|c|}
\hline \multicolumn{7}{|c|}{ Intake categories } & \multirow{2}{*}{$\begin{array}{c}\text { P- } \\
\text { trend }\end{array}$} \\
\hline Milk intake & ş/week & 3-4/week & 5-6/week & 1/day & $\geq 2 /$ day & Per time/day & \\
\hline No. of cases/pyrs & $91 / 240,746$ & $109 / 281,197$ & $150 / 383,471$ & $193 / 515,169$ & $284 / 784,756$ & & \\
\hline Age-adjusted RR & 1.00 & $1.05(0.79-1.38)$ & $1.04(0.80-1.35)$ & $0.95(0.74-1.21)$ & $0.96(0.76-1.21)$ & $\begin{array}{c}0.98(0.92- \\
1.04)\end{array}$ & 0.490 \\
\hline Adjusted RR ${ }^{1}$ & 1.00 & $1.04(0.79-1.38)$ & $1.04(0.79-1.35)$ & $0.95(0.73-1.23)$ & $0.92(0.70-1.21)$ & $\begin{array}{c}0.97(0.90- \\
1.04)\end{array}$ & 0.372 \\
\hline Adjusted RR ${ }^{2}$ & 1.00 & $1.05(0.79-1.39)$ & $1.04(0.79-1.36)$ & $0.93(0.71-1.21)$ & $0.84(0.62-1.13)$ & $\begin{array}{c}0.93(0.86- \\
1.02)\end{array}$ & 0.117 \\
\hline Cheese intake & s/month & 1-2/week & 3-4/week & $\square /$ week & & Per time/day & \\
\hline No. of cases/pyrs & $372 / 882,941$ & $254 / 737,596$ & $150 / 401,834$ & $51 / 182,968$ & & & \\
\hline Age-adjusted RR & 1.00 & $0.87(0.74-1.02)$ & $0.98(0.81-1.19)$ & $0.76(0.57-1.02)$ & & $\begin{array}{c}0.81(0.58- \\
1.12)\end{array}$ & 0.198 \\
\hline Adjusted RR ${ }^{1}$ & 1.00 & $0.89(0.75-1.04)$ & $1.00(0.82-1.23)$ & $0.78(0.57-1.07)$ & & $\begin{array}{c}0.84(0.58- \\
1.21)\end{array}$ & 0.343 \\
\hline Adjusted RR ${ }^{2}$ & 1.00 & $0.88(0.75-1.04)$ & $1.01(0.82-1.24)$ & $0.79(0.57-1.08)$ & & $\begin{array}{c}0.85(0.59- \\
1.20)\end{array}$ & 0.405 \\
\hline Ice cream intake & $\varsigma 3 /$ month & 1-2/week & 3-4/week & $\triangle 5 /$ week & & Per time/day & \\
\hline No. of cases/pyrs & $415 / 1,011,435$ & $244 / 693,028$ & $122 / 333,648$ & $46 / 167,228$ & & & \\
\hline Age-adjusted RR & 1.00 & $0.95(0.81-1.12)$ & $1.05(0.86-1.29)$ & $0.79(0.59-1.08)$ & & $\begin{array}{c}0.87(0.62- \\
1.22)\end{array}$ & 0.409 \\
\hline Adjusted RR ${ }^{1}$ & 1.00 & $0.96(0.82-1.14)$ & $1.05(0.85-1.30)$ & $0.76(0.55-1.05)$ & & $\begin{array}{c}0.83(0.57- \\
1.21)\end{array}$ & 0.331 \\
\hline Adjusted $\mathrm{RR}^{2}$ & 1.00 & $0.96(0.81-1.14)$ & $1.05(0.84-1.32)$ & $0.76(0.54-1.07)$ & & $\begin{array}{c}0.83(0.56- \\
1.23)\end{array}$ & 0.357 \\
\hline Dairy intake & 4/week & 5-6/week & 1-2/day & 3/day & $\geq 4 /$ day & Per time/day & \\
\hline No. of cases/pyrs & $99 / 261,026$ & $112 / 241,032$ & $329 / 905,744$ & $167 / 429,737$ & $120 / 367,800$ & & \\
\hline Age-adjusted RR & 1.00 & $1.26(0.96-1.65)$ & $1.00(0.80-1.25)$ & $1.03(0.80-1.31)$ & $0.95(0.73-1.24)$ & $\begin{array}{c}0.96(0.91- \\
1.03)\end{array}$ & 0.255 \\
\hline Adjusted RR ${ }^{1}$ & 1.00 & $1.25(0.95-1.64)$ & $0.98(0.76-1.25)$ & $0.96(0.72-1.27)$ & $0.88(0.64-1.23)$ & $\begin{array}{c}0.94(0.87- \\
1.02)\end{array}$ & 0.162 \\
\hline Adjusted RR ${ }^{2}$ & 1.00 & $1.24(0.94-1.63)$ & $0.96(0.75-1.23)$ & $0.87(0.63-1.19)$ & $0.81(0.57-1.15)$ & $\begin{array}{c}0.91(0.83- \\
1.00)\end{array}$ & 0.045 \\
\hline $\begin{array}{l}\text { Calcium intake } \\
(\mathrm{mg} / 1000 \mathrm{kcal})\end{array}$ & Q1 $(<318)$ & Q2 (318-386) & Q3 (386-487) & Q4 (487-627) & Q5 (>627) & Per quintile & \\
\hline No. of cases/pyrs & $176 / 437,694$ & $168 / 441,351$ & $147 / 441,060$ & $177 / 442,350$ & $159 / 442,884$ & & \\
\hline Age-adjusted RR & 1.00 & $0.93(0.75-1.15)$ & $0.78(0.63-0.97)$ & $0.95(0.78-1.18)$ & $0.84(0.68-1.04)$ & $\begin{array}{c}0.77(0.50- \\
1.20)\end{array}$ & 0.243 \\
\hline Adjusted RR ${ }^{1}$ & 1.00 & $0.96(0.77-1.18)$ & $0.83(0.67-1.04)$ & $1.07(0.85-1.34)$ & $0.85(0.68-1.07)$ & $\begin{array}{c}0.82(0.52- \\
1.30)\end{array}$ & 0.406 \\
\hline
\end{tabular}

Cancer Causes Control. Author manuscript; available in PMC 2021 October 01. 


\begin{tabular}{|c|c|c|c|c|c|c|c|}
\hline & & & Intake categories & & & & P- \\
\hline Adjusted $\mathrm{RR}^{2}$ & 1.00 & $0.93(0.75-1.15)$ & $0.79(0.63-1.00)$ & $0.99(0.77-1.26)$ & $0.75(0.57-0.99)$ & $\begin{array}{c}0.62(0.36- \\
1.09)\end{array}$ & 0.098 \\
\hline
\end{tabular}

${ }^{1}$ Adjusted for age; adolescent energy intake; race; family history of prostate cancer; education; marital status; cigarette smoking history; adult alcohol intake; adult waist circumference; body mass index at ages 18, 35, 50, and baseline; adolescent and adult physical activity; prostate-specific antigen and digital rectal examination screening history; diabetes history; father's occupation; attained height; and adult intake of whole milk, cheese, ice cream, total high-fat dairy products and calcium, as appropriate.

2

Adjusted for age; adolescent energy intake; race; family history of prostate cancer; education; marital status; cigarette smoking history; adult alcohol intake; body mass index at ages 18,35, 50, and baseline; adolescent and adult physical activity; prostate-specific antigen and digital rectal examination screening history; father's occupation; attained height; adult intake of whole milk, cheese, ice cream, total high-fat dairy products and calcium, as appropriate; and adolescent intake of grains, vegetables, fruits, potatoes, red meat, and sweets. 